\title{
Small Airways Response to Bronchodilators in Adults with Asthma or COPD: A Systematic Review
}

\author{
Mohammed A Almeshari (iD) ${ }^{1,2}$ \\ Nowaf Y Alobaidi iD 1,3 \\ Elizabeth Sapey (ID) \\ Omar Usmani (ID) \\ Robert A Stockley iD ${ }^{6}$ \\ James A Stockley iD
}

'Birmingham Acute Care Research Group, Institute of Inflammation and Ageing, University of Birmingham, Birmingham, BI5 2TT, UK;

${ }^{2}$ Rehabilitation Health Sciences Department, College of Applied Medical Sciences, King Saud University, Riyadh, Saudi Arabia; ${ }^{3}$ Respiratory Therapy Department, King Saud Bin Abdulaziz University for Health Sciences, Alahsa, Saudi Arabia; ${ }^{4}$ Acute Medicine, University Hospitals Birmingham NHS Foundation Trust, Birmingham, BI5 2GW, UK; ${ }^{5}$ Imperial College of London, London, UK; ${ }^{6}$ Department of Respiratory Medicine, University Hospitals Birmingham NHS Foundation Trust, Birmingham, UK; ${ }^{7}$ Lung Function \& Sleep Department, Respiratory Medicine, University Hospitals Birmingham NHS Foundation Trust, Queen Elizabeth Hospital Birmingham, Birmingham, UK
Background: Bronchodilator responsiveness (BDR) is commonly used in the diagnosis of lung disease. Although small airways dysfunction is a feature of asthma and COPD, physiological tests of small airways are not included in guidelines for BDR testing. This systematic review assessed the current evidence of BDR using small airways function in asthma and COPD.

Methods: The systematic review used standard methodology with the protocol prospectively registered on PROSPERO (CRD42020164140). Electronic medical databases (EMBASE and Medline) were searched using related keywords. Abstracts and full texts were screened independently by two reviewers. Studies that reported the change of physiological small airways function and $\mathrm{FEV}_{1}$ were included in the review. The revised Cochrane risk of bias tool for RCT and NIH quality assessment tool for cohort and cross-sectional studies were used to evaluate the studies.

Results: A total of 934 articles were identified, with 12 meeting the inclusion criteria. Ten studies included asthma patients, 1 study included COPD patients and 1 study included both asthma and COPD. A total of 1104 participants were included, of whom 941 were asthmatic, 64 had COPD and 109 were healthy controls. Studies were heterogeneous in design including the device, dose and time intervals for BDR assessment. A small airway BDR was seen for most tests in asthma and COPD, including oscillometry (R5-20, reactance (X5), area of reactance $(\mathrm{AX})$ and resonant frequency (Fres)) and Maximal Mid Expiratory Flow.

Conclusion: There is a measurable BDR in the small airways. However, with no consensus on how to assess BDR, studies were heterogeneous. Further research is needed to inform how BDR should be assessed, its clinical impact and place in routine clinical practice.

Keywords: asthma, COPD, bronchodilator, reversibility, small airways function

\section{Introduction}

Testing for bronchodilator responsiveness is currently included in the diagnosis of asthma and can help in differentiating asthma from other respiratory-related diseases such as chronic obstructive pulmonary disease (COPD). ${ }^{1}$ The term "reversibility" is often used but, in the 2019 spirometry standards update by the American Thoracic Society (ATS) and European Thoracic Society (ERS), the term 'responsiveness" was recommended, as "reversibility" may imply fully reversing airways obstruction. $^{2}$ The effort-dependent forced vital capacity (FVC) maneuver is usually used in a pre- and post-bronchodilator assessment with the forced expiratory volume in the first second $\left(\mathrm{FEV}_{1}\right)$ as the index usually reported to assess airways responsiveness.
Correspondence: Mohammed A Almeshari Rehabilitation Health Science Department, College of Applied Medical Sciences, King Saud University, P. Box I45 I I , Riyadh, ZIP 4545, Saudi Arabia

Tel +966508033880

Email malmeshari@ksu.edu.sa 
Evidence suggests that small airways dysfunction is prevalent in both asthma and COPD. ${ }^{3,4}$ Spirometry is the current gold standard to diagnose airways obstruction and maximal mid-expiratory flow (MMEF), also known as forced expiratory flow between $25 \%$ and $75 \%$ of FVC $\left(\mathrm{FEF}_{25-75}\right)$, and occasionally called MEF and $\mathrm{FEF}_{50}$, is the index parameter most commonly used to evaluate small airways function by spirometry. ${ }^{2,5,6}$ However, administering bronchodilators can change both the $\mathrm{FEV}_{1}$ and the FVC directly so, as FVC influences MMEF, a volume adjustment is needed to accurately evaluate any response when using MMEF. ${ }^{2}$

Short-acting beta2 agonists (SABA), such as salbutamol, are the most widely used bronchodilators for bronchodilator response (BDR) testing and are commonly delivered using a jet nebulizer or pressurized metered dose inhalers (pMDI) with a spacer. ${ }^{2}$ However, there are many factors which can impact on the results of BDR testing and, currently, there is no consensus regarding the dose, technique or device used. The latest ATS/ERS guidelines released in 2019 suggest that this should be decided by the healthcare professional providing care. ${ }^{2}$ In a previous guideline of the ATS/ERS task force, it was highlighted that dose standardization was needed to determine reversibility/response cut-off values. ${ }^{7}$

The effectiveness of aerosolized medication and the BDR is dependent on the deposition in the lungs which, in turn, is dependent on multiple factors, including the concentration of the drug, technique of delivery and the size of particles. ${ }^{8,9}$ There is no gold standard for BDR testing regimens and the type of medication, dosage, and time delay for post-assessment can vary, leading to difficulty in comparing results, although doses between 200 and $400 \mathrm{mcg}$ of salbutamol via pMDI are suggested. ${ }^{10-12}$ There are clear recommendations that patients should omit taking SABA for 4-6 hours before a baseline test; shortacting muscarinic antagonists (SAMA) for 12 hours before the test; long-acting beta2 agonists (LABA) for 24 hours before the test; Ultra-LABA for 36 hours before the test; long-acting muscarinic antagonists (LAMA) for 36-48 hours before the test. ${ }^{2}$

Different criteria have been suggested to define a "significant" BDR but a change in $\mathrm{FEV}_{1}$ of at least $160 \mathrm{~mL}$ is usually recommended due to the effort-dependent variability of the test especially following repeated measures. ${ }^{13}$ Significant BDR is defined as a change of over $12 \%$ from the baseline $\mathrm{FEV}_{1}$ and an absolute increase of more than $200 \mathrm{~mL}$ by ATS/ERS, ${ }^{14}$ and a change of over $15 \%$ from the baseline $\mathrm{FEV}_{1}$ with an increase of $200 \mathrm{~mL}$ in volume by the British Thoracic Society (BTS). ${ }^{15}$

Although BDR is thought to be important to differentiate between asthma and COPD, studies have indicated that it may not be discriminatory. ${ }^{16,17} \mathrm{BDR}$ is seen in some patients with COPD, although this can have day-to-day variability.${ }^{18,19}$ BDR may be important in the diagnosis and prognosis of asthma, ${ }^{20,21}$ but not all patients with diagnosed asthma have BDR. Nonetheless, in asthmatic patients with normal FEV ${ }_{1}$, MMEF has been reported below normal values, indicating small airways dysfunction as part of the disease paradigm. ${ }^{22}$ The usefulness of BDR in managing COPD patients is also unclear. Even in the absence of $\mathrm{FEV}_{1}$ improvement, Vital Capacity and Inspiratory Capacity can increase following inhaled bronchodilator use and these improvements are reflected in reduced dyspnea and increased exercise performance. ${ }^{23,24}$ This suggests that changes in $\mathrm{FEV}_{1}$ may not be the only marker to capture a treatment response.

Studies using small airway tests to assess BDR have reported improvements in these lung function parameters post-therapy. ${ }^{25,26}$ In COPD, there is evidence that small airways dysfunction might be the earliest pathological manifestation of disease (both pathologically and physiologically) and several studies reported a substantial loss of small airways or their function before the development of classical spirometric airflow obstruction. ${ }^{27-29}$

Pathological, physiological and radiological studies assessing the small airways recommend targeting them early in the course of COPD. ${ }^{27-30}$ In both asthma and COPD, inhaled extra-fine particle treatments have been developed specifically to target the smaller airways ${ }^{30}$ and more novel treatment trials are in progress. Understanding whether bronchodilator response can be assessed using tests of small airways function (SAF) would be important for clinical trials and assessing patient response to treatments.

The objective of this systematic review was to evaluate the current evidence of small airways response to shortacting inhaled bronchodilators in adults with asthma or COPD. Moreover, to evaluate the effectiveness of methods used in delivering aerosolized bronchodilators to the small airways and their function.

\section{Materials and Methods Protocol, Sources of Information and Search Strategy}

The protocol was registered in PROSPERO (registration number CRD42020164140). The review was written in 
accordance with the Preferred Reporting Items for Systematic Reviews and Meta-Analyses (PRISMA) guidelines. ${ }^{31}$ Through scoping, the following tests were selected to be included in the search, forced oscillometry (FOT), impulse oscillometry (IOS), forced expiratory flow at $50 \%$ of $\mathrm{FVC}\left(\mathrm{FEF}_{50}\right)$, single breath washout (SBW) and multiple breath washout (MBW). A complete searching strategy is provided in the Supplementary File (S1).

\section{Eligibility Criteria (PICO)}

Studies were considered for inclusion to the review if the selected small airways tests were conducted on adults diagnosed with either asthma or COPD, where both $\mathrm{FEV}_{1}$ and the change in small airways function due to BDR tests were reported. The eligibility criteria are detailed in Table 1.

\section{Study Selection and Data Extraction}

Search results were imported into EndNote 9.1 (Clarivate Analytics) and duplicates were removed. The screening was conducted using Rayyan software ${ }^{32}$ to facilitate the screening between reviewers. Abstracts were screened blindly and independently by MAA and NYA using the predefined inclusion and exclusion criteria. Disagreements were resolved through discussion. Full-text articles were obtained and imported into EndNote by MAA and similar abstract screening method was used in screening full texts for suitability.

Using a custom, piloted data extraction form, data were extracted by MAA and NYA and then compared for consistency and accuracy. SAF tests used to assess the BDR, dose of medication, time interval after bronchodilator administration, characteristics of populations, smoking history, and devices used to assess BDR were extracted to aid the narrative synthesis of the studies. The categorization of the studies was based on the SAF test and the disease (asthma and COPD).

\section{Quality Assessment}

The quality assessment of included studies was undertaken blindly by two independent reviewers. The revised Cochrane risk of bias tool for randomized controlled trials (RCT) was used to assess the quality and likelihood of bias in the RCT studies included, with the risk of bias classified as high, some concern or low for each study. ${ }^{33}$ The National Institute of Health (NIH) tool for quality assessment of cohort and cross-sectional studies was used to assess the quality of cohort and cross-sectional studies, with the quality classified as good, fair or poor. $^{34}$

\section{Data Synthesis}

Meta-analysis was considered where homogeneous results were provided. Otherwise, data were drawn into figures.

\section{Results Study Selection}

Through the electronic search, a total of 934 abstracts were identified, of which 817 were screened in the full-text phase and a total of 12 studies met the inclusion criteria. A PRISMA flow chart is shown in Figure 1.

Table I The PICO (Population, Intervention, Comparator, Outcome) and Study Design for the Systematic Review

\begin{tabular}{|c|c|c|}
\hline PICO & Inclusion Criteria & Exclusion Criteria \\
\hline \multirow[t]{2}{*}{ Population } & \multirow[t]{2}{*}{ - Adult patients aged at least 18 years with a clinical diagnosis of COPD or Asthma } & $\begin{array}{l}\text { - Other chronic lung diseases such as } \\
\text { cystic fibrosis. }\end{array}$ \\
\hline & & - Patients younger than 18 years old \\
\hline Intervention & $\begin{array}{l}\text { Small airways function (IOS, FOT, MMEF, } \mathrm{FEF}_{50}, \mathrm{MBW}, \mathrm{SBW} \text { ) response to } \mathrm{BDR} \text { using short } \\
\text { acting beta2 agonist (SABA) via various aerosol delivery devices. }\end{array}$ & \\
\hline Comparator & BDR in conventional lung function $\left(\mathrm{FEV}_{\mathrm{l}}\right)$ & \\
\hline Outcome & Change in small airways function after administrating the bronchodilator therapy. & \\
\hline Study design & $\begin{array}{l}\text { Randomised Control Trials (RCT), Cohort, Cross-sectional, Longitudinal, Case-series }>10 \\
\text { patients, Systematic reviews }\end{array}$ & $\begin{array}{l}\text { Reviews, Editorials, Case series of } \\
<10 \text { Patients, Case reports }\end{array}$ \\
\hline
\end{tabular}

Note: The Systematic review included the following inclusion and exclusion criteria, as described above.

Abbreviations: COPD, chronic obstructive pulmonary disease; IOS, impulse oscillometry; FOT, forced oscillometry; FEV mean mid-maximal expiratory flow; $\mathrm{FEF}_{50}$, forced expiratory flow at $50 \%$ of $\mathrm{FVC}$. 


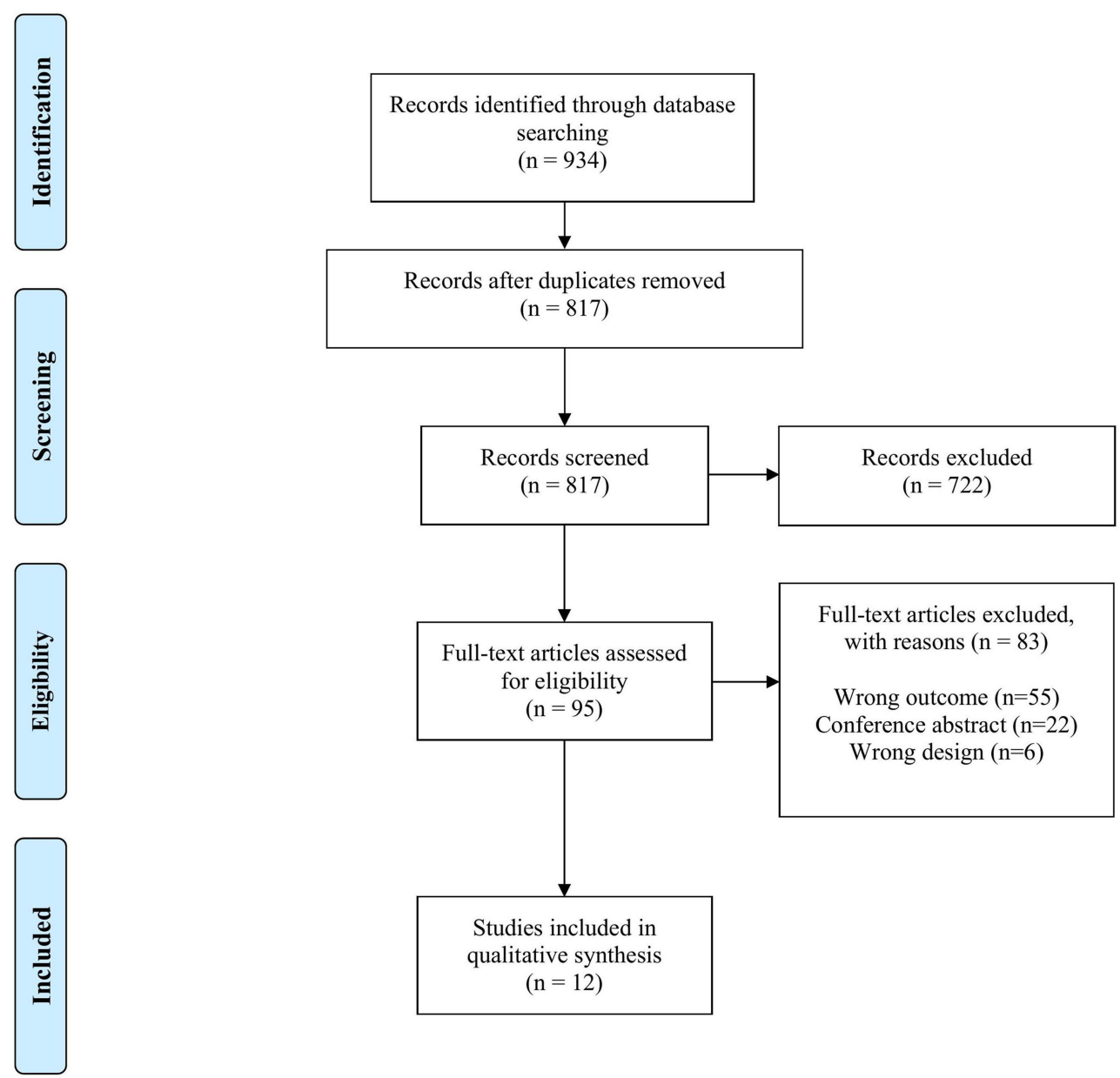

Figure I PRISMA flow chart showing the studies identification process from EMBASE and Medline databases.

Notes: Adapted from: Moher D, Liberati A, Tetzlaff J, Altman DG. Preferred reporting items for systematic reviews and meta-analyses: the PRISMA statement. PLoS Med. 2009;6(7):el $000097 .^{62}$ Creative Commons.

\section{Study Characteristics}

Ten studies included patients with asthma, ${ }^{35-44}$ one study included COPD patients, ${ }^{26}$ and one study included both asthmatic and COPD patients. ${ }^{45}$ The total number of the participants included from all studies was 1104, of whom 941 were asthmatic, 64 COPD patients and 109 healthy control subjects. Studies were conducted in different countries from three continents. Three studies were conducted in the United Kingdom, two in the United States, and one study in each of the following countries: India, Iran, Italy, Japan, Korea, Lebanon, and Portugal. In Table 2, the main characteristics of each study are shown.

There were differences in the reported diagnostic criteria for asthma. In studies of asthma, four used Global Initiative of Asthma (GINA) guidelines ${ }^{38,40,43}$ and one study used a specific criterion (stable asthma who showed at least $15 \%$ BDR after SABA inhalation within 12-month prior starting the study). ${ }^{42}$ However, six of the studies that included asthmatic patients did not specify the diagnostic criteria. ${ }^{35-37,39,41,44}$ In studies of COPD, the Global Initiative for Chronic Obstructive Lung Disease (GOLD) criteria were used for COPD diagnosis. ${ }^{26,45}$ None of the included studies reported correction of MMEF in relation to FVC post-bronchodilation.

Only seven of the included studies defined the criteria for significance of BDR test. Those seven studies used the ATS/ERS criteria for defining significant BDR $(\geq 12 \%$ and $\geq 200 \mathrm{~mL})^{35,38-40,43-45}$ while in five, the criteria were not specified. $26,36,37,41,42$

There were different methods used in delivering aerosolized medications. Eight studies used pMDIs, two used small volume jet nebulizers (SVN), one used dry powder inhalers (DPI) and one used dosimeter. None of the included studies reported the use of extra-fine aerosol delivery devices such as vibrating mesh nebulizers. Only two studies compared modalities of delivering bronchodilators, 


\begin{tabular}{|c|c|c|c|c|c|c|c|c|c|c|c|c|c|c|c|c|c|c|}
\hline 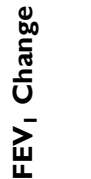 & 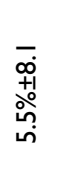 & & 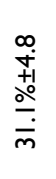 & 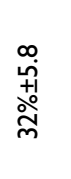 & 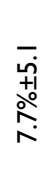 & & 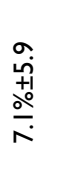 & & 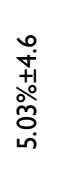 & & 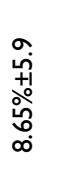 & & 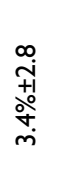 & & $\begin{array}{l}\stackrel{\circ}{\circ} \\
\text { O }\end{array}$ & $\begin{array}{l}\stackrel{\circ}{\hat{~}} \\
\stackrel{\text { in }}{ }\end{array}$ & 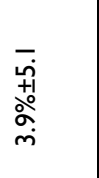 & 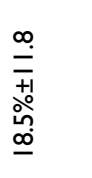 \\
\hline 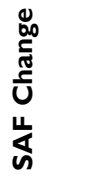 & 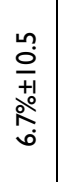 & 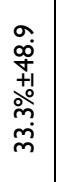 & $\begin{array}{l}0 \\
\infty \\
0 \\
+1 \\
0 \\
0 \\
\dot{7} \\
\dot{7}\end{array}$ & 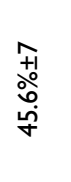 & 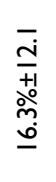 & 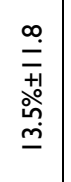 & 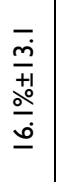 & 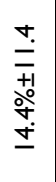 & 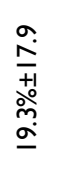 & 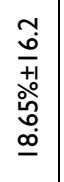 & 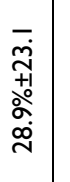 & 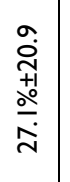 & 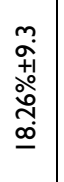 & $\begin{array}{l}a \\
\infty \\
+1 \\
+1 \\
\stackrel{0}{0} \\
\underline{\underline{n}}\end{array}$ & 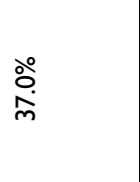 & $\begin{array}{l}\stackrel{\circ}{\circ} \\
\dot{f}\end{array}$ & 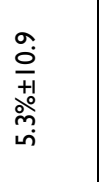 & 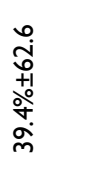 \\
\hline 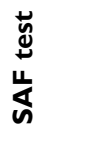 & 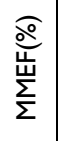 & $\begin{array}{l}\widehat{\circ} \\
\text { 号 } \\
\text { 岃 }\end{array}$ & 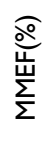 & 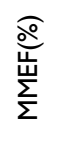 & 离 & 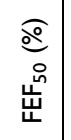 & 离 & 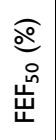 & 总 & 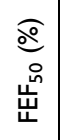 & 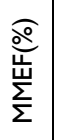 & 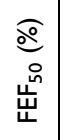 & 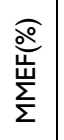 & $\begin{array}{l}\text { @ } \\
\text { 足 } \\
\text { 出 }\end{array}$ & 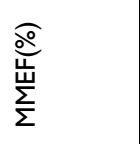 & 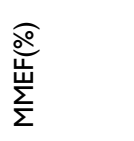 & 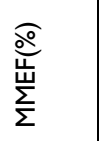 & 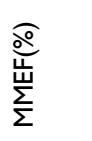 \\
\hline 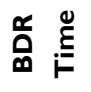 & $\underline{\underline{n}} \cdot \overline{\bar{\varepsilon}}$ & & 8 & & 으 & & 으 & & ণి & & & & & & 号 & & 으 돝 & \\
\hline 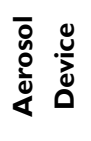 & $\frac{+}{\overline{0}} \overline{\grave{d}}$ & & $\overline{\sum_{\alpha}}$ & 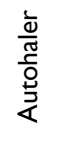 & 离 & & 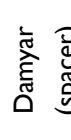 & & $\overline{\bar{\Sigma}}$ & & & & & & 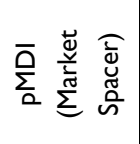 & 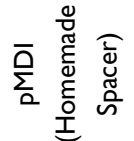 & 产 & \\
\hline 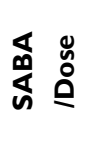 & 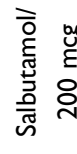 & & 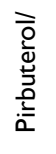 & & 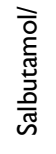 & & & & 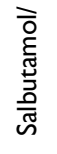 & & & & & & 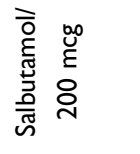 & & 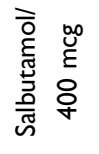 & \\
\hline 品 & 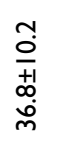 & & $\frac{\infty}{+1}$ & & $\frac{a}{\sigma}$ & & $\frac{\stackrel{\sigma}{\sigma}}{\frac{i}{+1}}$ & & 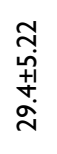 & & $\frac{\hat{0}}{m} \stackrel{\infty}{+}$ & & 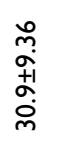 & & $\frac{\infty}{m}$ & & $\frac{\stackrel{\sigma}{\bar{T}}}{\stackrel{+}{\frac{1}{0}}}$ & 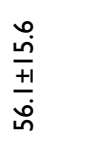 \\
\hline 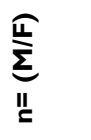 & 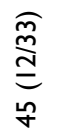 & & 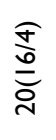 & & 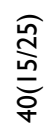 & & 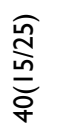 & & $\begin{array}{l}\widehat{o} \\
\substack{o \\
\infty} \\
\stackrel{0}{0} \\
\underline{0}\end{array}$ & & $\begin{array}{l}\frac{1}{\alpha} \\
\frac{\infty}{\infty} \\
\stackrel{\infty}{\tilde{m}} \\
\underline{\infty}\end{array}$ & & 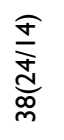 & & 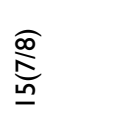 & & 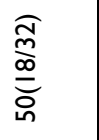 & 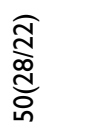 \\
\hline $\begin{array}{l}\frac{2}{0} \\
\frac{0}{7} \\
\frac{0}{2} \\
\frac{0}{0}\end{array}$ & 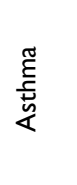 & & 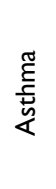 & & 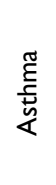 & & & & 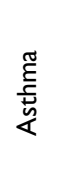 & & 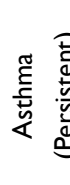 & & 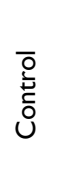 & & 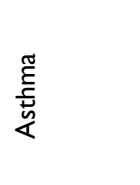 & & 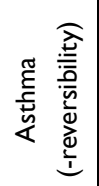 & 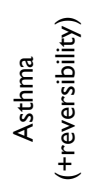 \\
\hline 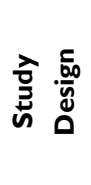 & 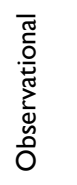 & & 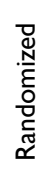 & 兽 & 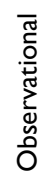 & & & & 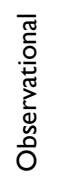 & & & & & & 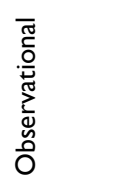 & & 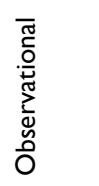 & \\
\hline $\begin{array}{l}\frac{0}{x} \\
\text { ते } \\
\text { मै }\end{array}$ & 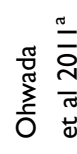 & & 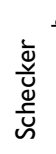 & & 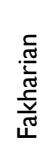 & & & & 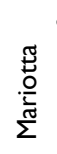 & & & & & & 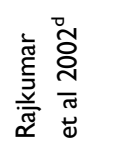 & & 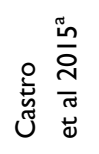 & \\
\hline
\end{tabular}




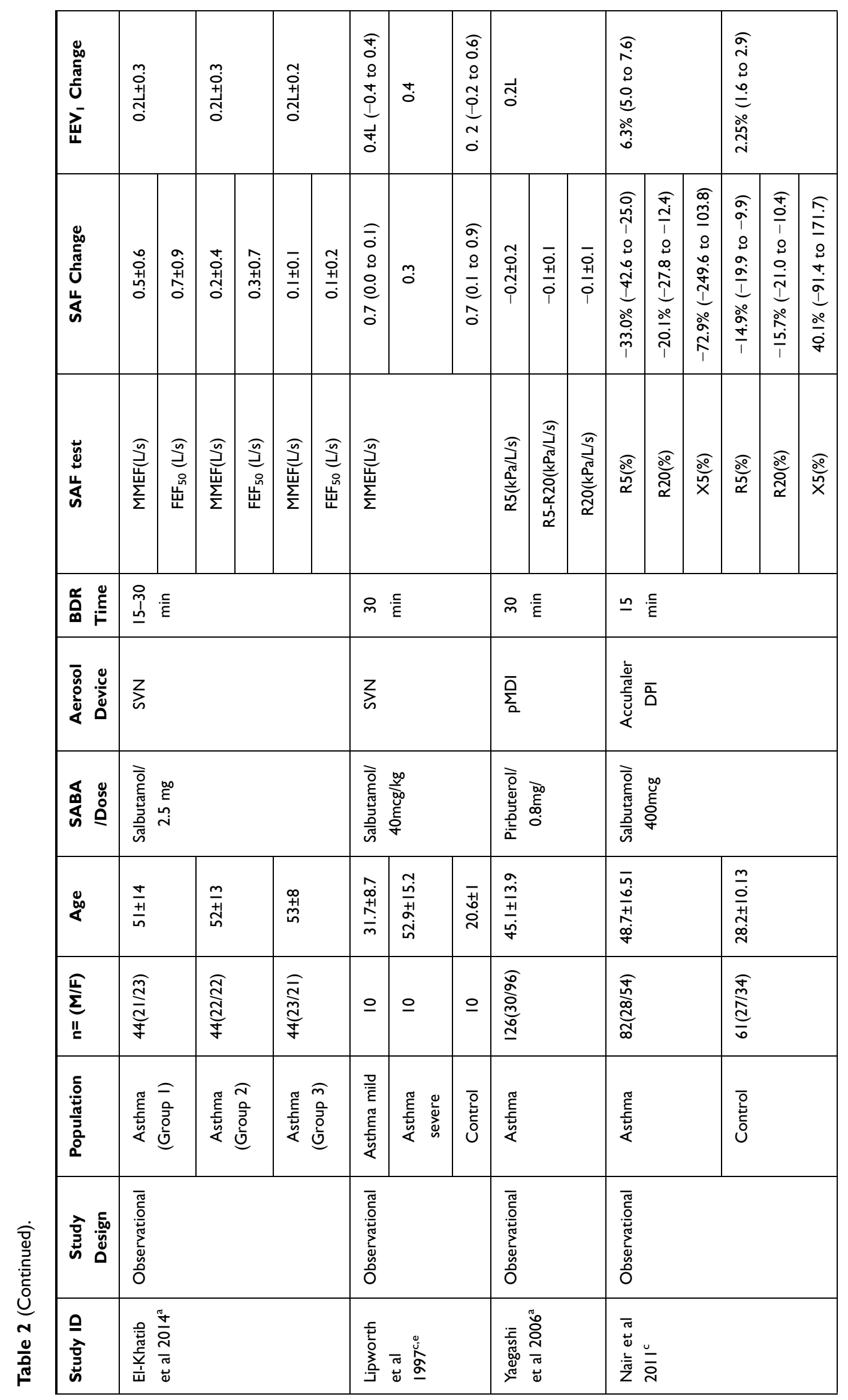




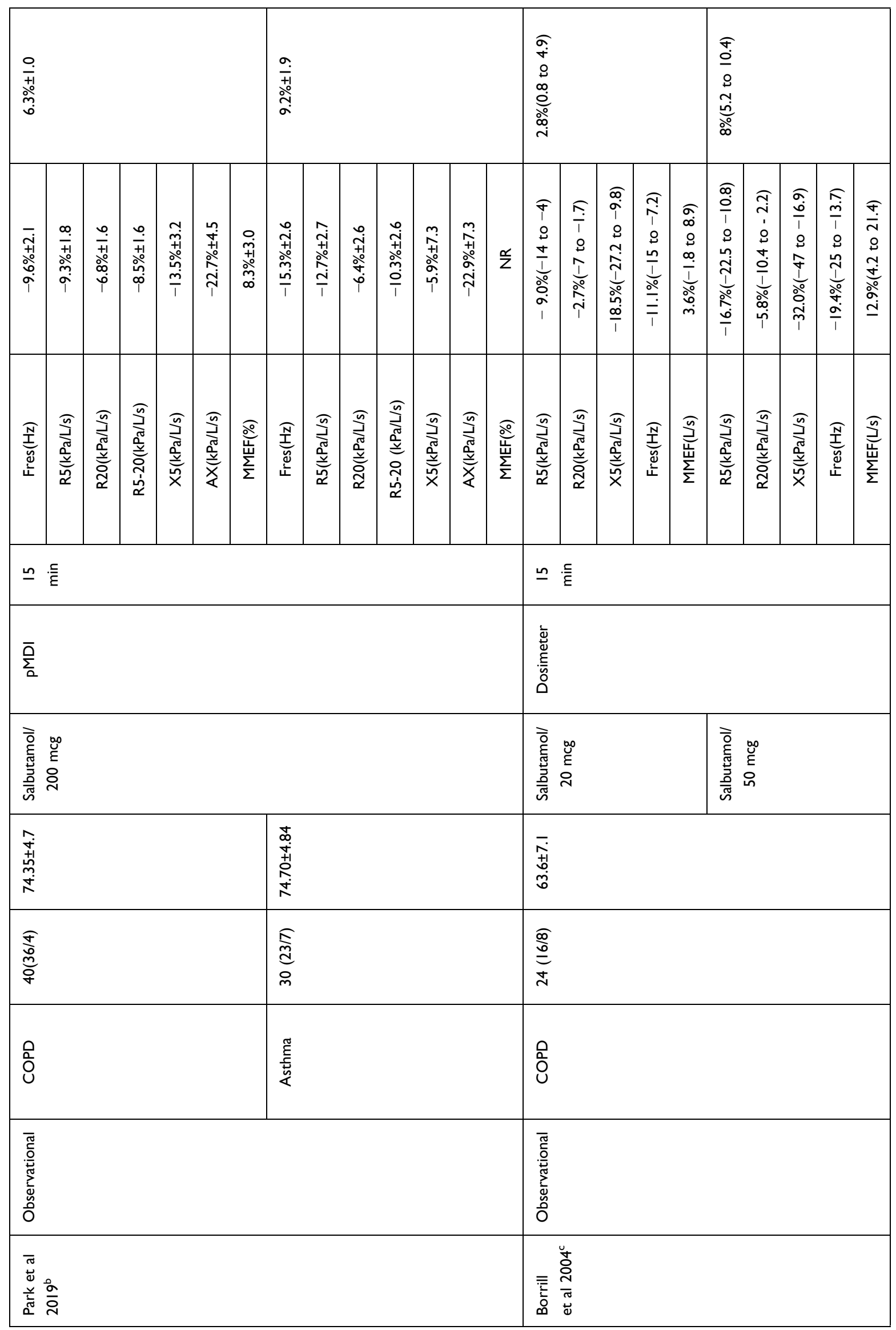




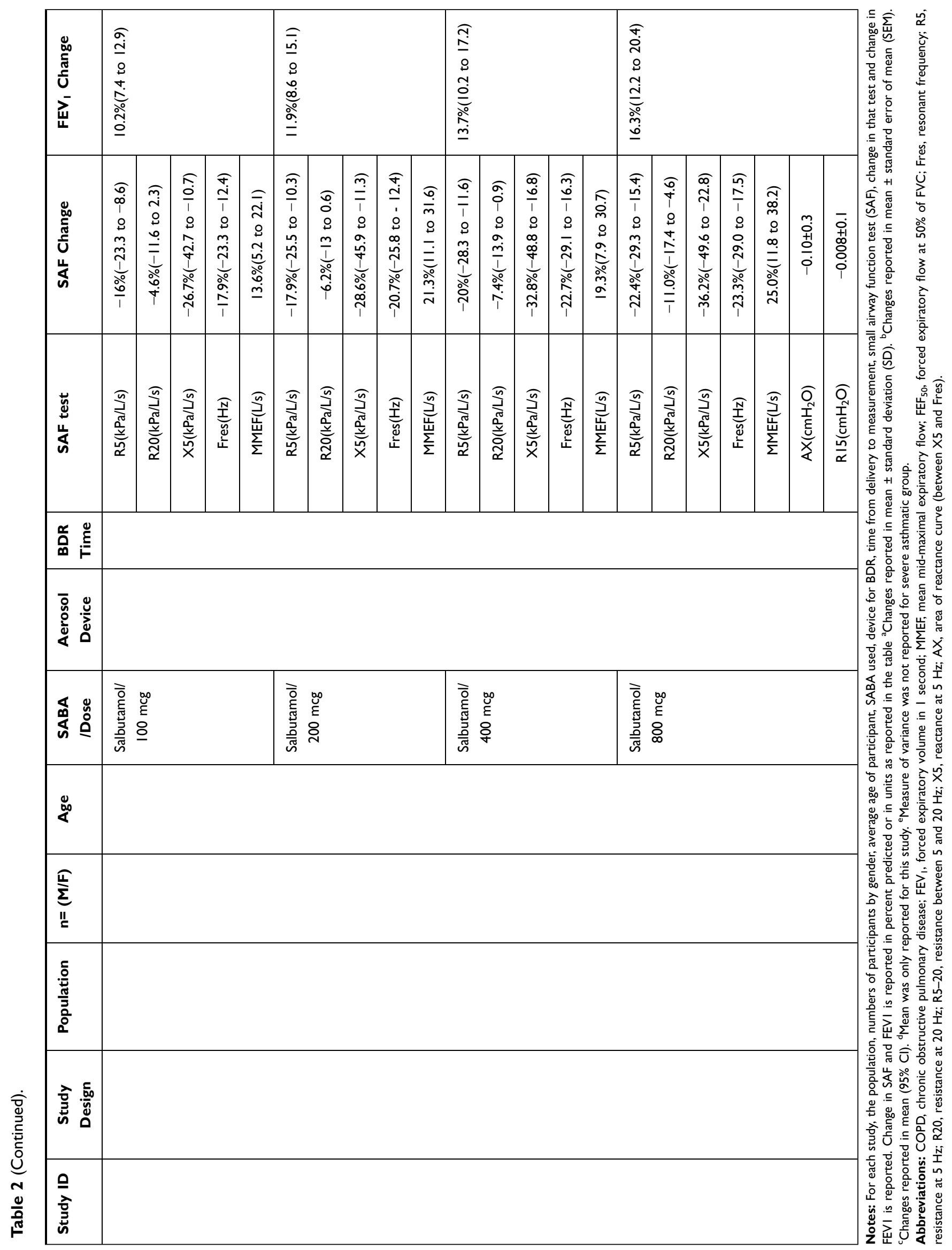


which was a comparison between spacers. ${ }^{36,41}$ One study compared two types of inhalers: a standard pMDI and an Autohaler (a breath-actuated pMDI). ${ }^{42}$ All studies used SABA, of which 10 used salbutamol and 2 used pirbuterol. Dosages were also different between studies but mostly ranged between 200 and $400 \mathrm{mcg}$ of salbutamol or equivalent. Tests used for assessing SAF were spirometry (MMEF, $\mathrm{FEF}_{50}$ ) in 10 studies and oscillometry in four. None of the included studies reported using MBW or SBW technique.

There were also differences in reporting the outcomes of BDR response. Absolute change of the parameters was reported in three of the studies ${ }^{35,37,44}$ whereas the change in $\%$ predicted in one study. ${ }^{39}$ The percentage of change was reported in eight studies, ${ }^{26,36,38,40-43,45}$ but most did not indicate if the percentage of change was derived from the absolute values or $\%$ predicted. Of the studies reporting percentage of a change, only two $0^{38,40}$ reported the method of obtaining \% change using absolute values with the following conventional formula: [(post-treatment - pre-treatment)/pre-treatments] $* 100$.

Meta-analysis was not considered feasible due to non-conformity of studies with respect to demographics, disease severity stages, methods used in delivering bronchodilators, drug type/dose, the time intervals between bronchodilation administration and tests differing between studies. A feature of all the studies, however, was the wide spread of patient responses, with large measures of variance across studies, suggesting marked heterogeneity between individuals and their responses.

\section{Quality Assessment}

The revised Cochrane risk of bias tool was used for one study, which was the only $\mathrm{RCT}^{42}$ Here, there was an overall high risk of bias, but there was a low risk of bias around deviation from the intervention or the measurement of the outcome.

The rest of the studies were assessed with the NIH tool for observational cohort and cross-sectional studies. The questions in all domains (D) of the NIH tool were answerable except that of D8, which relates to exposure to the outcome and was considered not applicable to the included studies. The assessment showed an overall good quality in 6 studies, ${ }^{26,35,40,43-45}$ fair quality in two $^{38,39}$ and poor quality in three. ${ }^{36,37,41} \mathrm{~A}$ graph of NIH quality assessment is shown in the Supplementary File (S2).

\section{Result of Individual Studies Spirometry (MMEF, FEF 50 )}

\section{Asthma}

Eight of the 12 studies reported BDR of MMEF, $\mathrm{FEF}_{50}$ or both in asthmatic patients. ${ }^{35-38,40-43}$ Ohwada et $\mathrm{al}^{40}$ recruited 45 non-smoking patients diagnosed with asthma but treatment-naive. The BDR assessment was carried out using $200 \mathrm{mcg}$ of salbutamol via pMDI and spacer. Fifteen minutes after inhaling the salbutamol, patients were reassessed. All results are reported as mean and standard deviation $( \pm \mathrm{SD})$. A non-significant change of $6.7 \pm 10.5 \%$ change in MMEF was described. In contrast, a significant change in $\mathrm{FEF}_{50}$ of $33.3 \pm 48.9 \%$ was found and statistically significant $(\mathrm{p}=0.001)$ as well as a $5.7 \pm 8.1 \%$ change $(\mathrm{p}=0.004)$ in $\mathrm{FEV}_{1}$. However, the change of $\mathrm{FEV}_{1}$ did not meet the ATS/ERS criterion for significant BDR.

Schecker et $\mathrm{al}^{42}$ assessed two types of inhalers to determine if device influenced the medication deposition or response, the standard pMDI and the Autohaler. Patients were tested on two separate days to assess consistency with both devices. Pirbuterol $0.4 \mathrm{mg}$ was used as the bronchodilator and spirometry results were reported after 60 minutes. Similar changes in both devices were found for MMEF and $\mathrm{FEV}_{1}$. A mean change in MMEF of 44.6 $\pm 8.6 \%$ was reported using a standard pMDI and $45.6 \pm 7.0$ using the Autohaler. Mean change in $\mathrm{FEV}_{1}$ was $31.1 \pm 4.8 \%$ using a standard pMDI and 32.0 \pm 5.8 using the Autohaler, meeting ATS/ERS criteria for significant BDR for both inhalers, although there were no significant differences between the two devices for results for either MMEF or $\mathrm{FEV}_{1}$.

Fakharian et $\mathrm{al}^{36}$ conducted a study to compare the BDR of 2 spacers (Asmyar and Damyar). The authors reported the change in MMEF and $\mathrm{FEF}_{50} 10$ minutes after administering $400 \mathrm{mcg}$ of salbutamol and included only non-smokers with mild to moderate asthma. The change in MMEF and $\mathrm{FEF}_{50}$ using Asmyar was 16.3 $\pm 12.1 \%$ and $13.5 \pm 11.8 \%$, respectively whereas, in Damyar, the change was $16.1 \pm 13.1 \%$ and $14.4 \pm 11.4 \%$, respectively. The change in $\mathrm{FEV}_{1}$ was reported to be 7.7 $\pm 5.1 \%$ in Asmyar and $7.10 \pm 5.91 \%$ in Damyar. There were no differences between the spacers for any of the indices and subjects did not meet the ATS/ERS criteria for BDR in $\mathrm{FEV}_{1}$.

Mariotta et $\mathrm{al}^{38}$ reported MMEF and $\mathrm{FEF}_{50}$ in asthmatic patients (with either intermittent or persistent symptoms) and control subjects. The 3 groups were tested for 
BDR with $200 \mathrm{mcg}$ of salbutamol and had spirometry test assessed after 20 minutes. The authors reported a mean change in MMEF of $19.3 \pm 17.9 \%, 28.9 \pm 23.1 \%$ and 18.3 $\pm 9.3 \%$ in intermittent, persistent and control, respectively. $\mathrm{FEF}_{50}$ change was reported to be $18.7 \pm 16.2 \%, 27.1 \pm 20.9 \%$ and $15.2 \pm 8.9 \%$ and $\mathrm{FEV}_{1}$ change was reported to be 5.0 $\pm 4.6 \%, 8.7 \pm 5.9 \%$ and $3.4 \pm 2.8 \%$ for the same groups. However, once again, the changes of $\mathrm{FEV}_{1}$ did not meet the ATS/ERS criteria for BDR in any group.

Rajkumar et $\mathrm{al}^{41}$ studied the difference between commercial and home-made spacers. Percentage of change in MMEF was reported after administering $200 \mathrm{mcg}$ of salbutamol but the time to post-bronchodilator testing was not reported. In this study, although the mean $\%$ change was reported, measure of variance was not. The change of MMEF was $37.0 \%$ and $47.1 \%$ when using commercial spacers versus home-made, respectively. $\mathrm{FEV}_{1}$ change was $19.0 \%$ and $22.7 \%$ for commercial and home-made spacers, respectively, which is (on average) above the $12 \%$ threshold of the ATS/ERS BDR criterion for both groups. There was no difference in response between the two spacers.

Castro et $\mathrm{al}^{43}$ included asthmatic patients with a confirmed history of airway reversibility consistent with the ATS/ERS 2005 guidelines as well as matched asthmatic patients without evidence of airway reversibility. Smoking patients, those under 20 years of age and patients who had a recent exacerbation of asthma were excluded from the study. Salbutamol (400 mcg) was used to assess BDR, and testing was completed ten minutes post-bronchodilator. The mean change $( \pm \mathrm{SD})$ in MMEF in the patients with a history of reversibility was $39.4 \pm 62.6 \%$ opposed to those without reversibility $5.3 \pm 10.9 \%$. The average $\mathrm{FEV}_{1}$ change $( \pm \mathrm{SD})$ was $18.5 \pm 11.8 \%$ and $3.9 \pm 5.1 \%$ in patients with reversible and non-reversible airflow, respectively, confirming that the group with previously noted reversibility once again met the ATS/ERS criterion for BDR as a $\%$ change.

Figure 2 summarizes these results by showing the average $\%$ change and the absolute change of MMEF and $\mathrm{FEF}_{50}$ in comparison to $\mathrm{FEV}_{1}$ and $\mathrm{FVC}$ in asthmatic patients. For all studies, there was a greater average \% change in tests of SAD than $\mathrm{FEV}_{1}$.

El-Khatib et al $^{35}$ designed a study to compare the effectiveness of using Heliox to reduce viscosity compared to medical air when nebulizing bronchodilators. The authors randomized asthma patients in a cross-over design so that each patient received albuterol $2.5 \mathrm{mg}$ using one or other method for nebulization on 2 different days (thus acting as their own control). Patients were grouped based on their baseline $\mathrm{FEV}_{1}$ results (all \% predicted: $\geq 80 \%$ (Group 1), $<80 \%$ to $>50 \%$ (Group 2) and $\leq 50 \%$ (Group $3)$ ) and absolute values of change were reported. Using medical air, mean changes of $0.54 \mathrm{~L} / \mathrm{s} \pm 0.63$ in $\mathrm{MMEF}$ and $0.67 \mathrm{~L} / \mathrm{s} \pm 0.91$ in $\mathrm{FEF}_{50}$ were reported in group 1. In group 2, a mean change in MMEF and $\mathrm{FEF}_{50}$ were $0.20 \mathrm{~L} / \mathrm{s} \pm 0.43$ and $0.33 \mathrm{~L} / \mathrm{s} \pm 0.68$, respectively. In group 3 , mean changes in $\mathrm{MMEF}$ and $\mathrm{FEF}_{50}$ were $0.10 \mathrm{~L} / \mathrm{s} \pm 0.13$ and $0.09 \mathrm{~L} / \mathrm{s}$

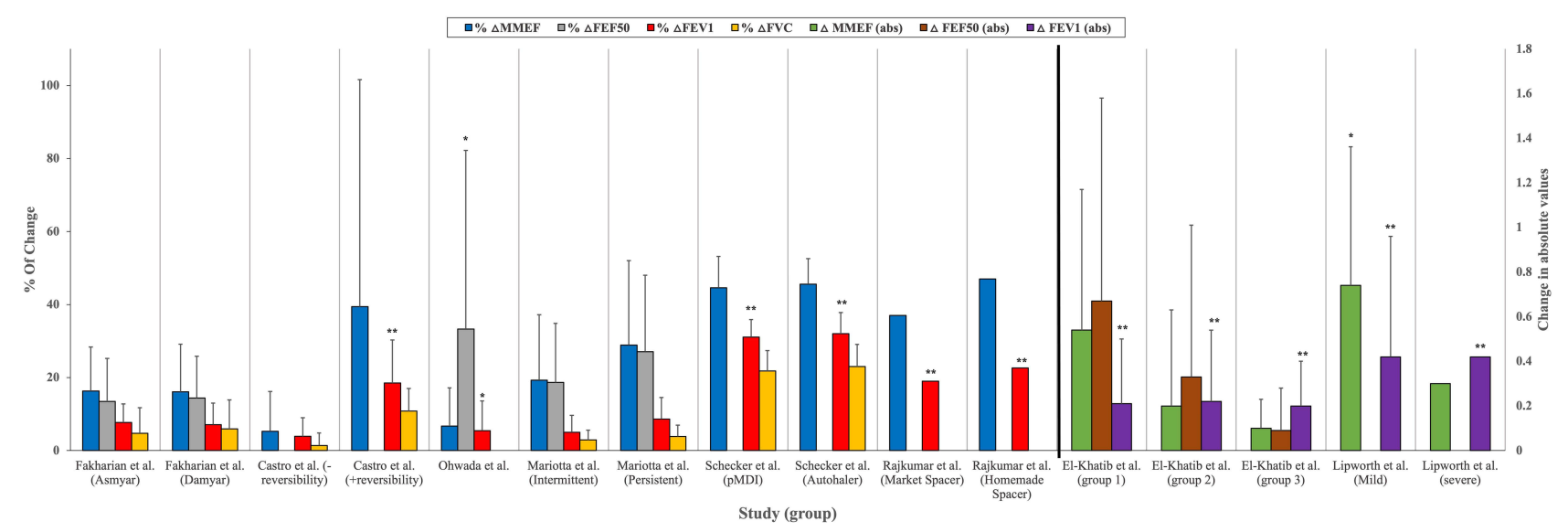

Figure 2 The average percentage change and absolute change in MMEF, FEF $50, \mathrm{FEV}_{\text {, }}$ and FVC across asthma studies.

Notes: Left vertical axis is \% of change in $\mathrm{MMEF} \mathrm{FEF}_{50}, \mathrm{FEV}_{1}$ and $\mathrm{FVC}$ in asthmatic patients. Right Vertical axis is absolute change in $\mathrm{MMEF} \mathrm{FEF}_{50}$, $\mathrm{FEV}_{1}$. Data presented are means \pm standard deviation (SD). Included data has been taken and adapted from Fakhrian et al, ${ }^{35}$ Castro et al, ${ }^{43}$ Ohwada et al, ${ }^{40}$ Mariotta et al, ${ }^{38}$ Schecker et al, ${ }^{42}$ Rajkumar et al, ${ }^{41}$ Elkhatib et al, ${ }^{36}$ and Lipworth et al. ${ }^{37}$ Measure of variances is not displayed in the error bars for Rajkumar et al ${ }^{41}$ and severe asthmatic patients in Lipworth et al ${ }^{37}$ because SD was not reported. *BDR is statistically significant. **BDR is clinically significant according to ATS/ERS criteria.

Abbreviations: MMEF, mean mid-maximal expiratory flow; $\mathrm{FEV}_{1}$, forced expiratory volume in I second; FVC, forced vital capacity; $\mathrm{FEF}_{50}$, forced expiratory flow at $50 \%$ of FVC. 
\pm 0.19 , respectively. The mean change of $\mathrm{FEV}_{1}$ was reported to be $0.21 \mathrm{~L} \pm 0.29$ in Group $1,0.22 \mathrm{~L} \pm 0.32$ in Group 2 and $0.20 \mathrm{~L} \pm 0.20$ in Group 3 which, on average, met the ATS/ERS criteria for significant BDR in all groups.

Lipworth et $\mathrm{al}^{37}$ conducted a study to assess the lungs' absorption of nebulized salbutamol (using a weight adjusted dose of $40 \mathrm{mcg} / \mathrm{kg}$ ) with lung physiology measured at baseline and 30 minutes after treatment. The authors recruited participants with mild and severe asthma as well as healthy controls. Thirty participants were included, with 10 in each group. Of note, 95\% confidence intervals were only reported for the healthy controls and mild groups, with no explanation as to why these data were omitted in the severe asthma group. The mean change of MMEF in L/s (95\% CI) was reported as 0.74 (0.04 to 0.93 ) in mild patient, 0.30 in severe patients and 0.69 ( 0.09 to 0.88$)$ in the control group. The mean change in $\mathrm{FEV}_{1}(95 \% \mathrm{CI})$ was $0.42 \mathrm{~L}(-0.38$ to 0.39$)$ in mild patients, $0.42 \mathrm{~L}$ in severe patients and $0.22 \mathrm{~L}(-0.18$ to 0.59 ) in the control group, meeting average ATS/ERS criteria for significant BDR in all groups. In Figure 2, the mean change of $\mathrm{MMEF}(\mathrm{L} / \mathrm{s})$ and $\mathrm{FEF}_{50}(\mathrm{~L} / \mathrm{s})$ in comparison to $\mathrm{FEV}_{1}(\mathrm{~L})$ is shown in the asthmatic patients from the studies by El-Khatib et $\mathrm{al}^{38}$ and Lipworth et al. ${ }^{40}$

Across all studies in asthma, BDR as measured using small airways tests appeared to show a greater difference than $\mathrm{FEV}_{1}$ (especially in milder disease) but had higher variability. In studies that assessed BDR in asthmatic subjects, only 5/10 studies met the ATS/ERS criteria for BDR of $\mathrm{FEV}_{1}$. $35,37,41-43$

\section{COPD}

Two studies reported BDR using MMEF in COPD patients. $^{26,45}$ Borrill et al $^{26}$ recruited 24 patients with COPD to compare IOS, airway resistance measured by body plethysmography and spirometry (including MMEF) to find the most reliable method for evaluating BDR. In this study, short-acting bronchodilators, long-acting beta2 agonists and tiotropium were withheld for 6 hours, 12 hours and 24 hours, respectively prior to the study day. Salbutamol (administered via dosimeter) was given in ascending doses of $20 \mathrm{mcg}, 50 \mathrm{mcg}, 100 \mathrm{mcg}$, $200 \mathrm{mcg}, 400 \mathrm{mcg}$ and $800 \mathrm{mcg}$, to assess the BDR and lung function was reassessed 15 minutes after each dose. In this study, MMEF showed statistically significant improvements $(\mathrm{p}<0.05)$ at doses of $200 \mathrm{mcg}$ and $400 \mathrm{mcg}$ with mean $(95 \% \mathrm{CI})$ of $21.3 \%$ (11.1 to 31.6$)$ and $19.3 \%$ (7.9 to 30.7 ), respectively. In contrast, the mean change of $\mathrm{FEV}_{1}$ showed statistically significant improvement $(\mathrm{p}<0.05)$ starting from a dose of $100 \mathrm{mcg}$, showing \% change of $10.2 \%$ ( 7.4 to 12.9$)$ and $11.9 \%$ (8.6 to 15.1 ) after a dose of $100 \mathrm{mcg}$ and $200 \mathrm{mcg}$, respectively. However, the ATS/ERS criteria for significant BDR with $\mathrm{FEV}_{1}$ were only met at a dose of $400 \mathrm{mcg}$ and $800 \mathrm{mcg}$ : average $13.7 \%$ (10.2 to 17.2 ) and $16.3 \%$ (12.2 to 20.4 ), respectively. Figure 3 summarizes these \% changes in MMEF and $\mathrm{FEV}_{1}$ using the different doses of salbutamol.

A recent prospective study by Park et $\mathrm{al}^{45}$ was conducted to assess BDR using IOS compared to spirometry in 40 elderly patients with COPD. In this study, patients were required to have no change in their prescribed medications for at least 4 weeks before the study but there were no details of when or if medications were paused prior to measurements. Albuterol was administered as two puffs of $100 \mathrm{mcg}$ via pMDI to assess BDR and the time interval between the inhalation and post-bronchodilator measurements was 15 minutes. The authors performed IOS before spirometry in all patients. In this study, the COPD patients were compared with 30 asthmatic patients and MMEF (referred to in the study as $\mathrm{FEF}_{25-75}$ ) was also used to assess the BDR. Following administration of albuterol, the mean change in MMEF was 8.6\% (SEM 3.0). The mean change in $\mathrm{FEV}_{1}$ of $6.3 \%$ predicted (1.0 SEM) did not reach the ATS/ERS criteria for BDR. It was not reported if any changes reached statistical significance.

\section{Oscillometry (R5, R5-20, X5, AX, Fres)}

\section{Asthma}

Three studies reported the BDR using oscillometry. ${ }^{39,44,45}$ Yaegashi et $\mathrm{al}^{44}$ retrospectively analysed data from asthmatic patients who underwent both spirometry and oscillometry. Patients with COPD or any other disorder of airflow obstruction that was not diagnosed as asthma were excluded as were patients with a smoking history of more than 10 pack years. Pirbuterol $0.8 \mathrm{mg}$ was administered via pMDI, but spacer use was not reported. BDR tests were carried out 30 minutes after the administration of the bronchodilator. The mean change $( \pm \mathrm{SD})$ was reported in $\mathrm{kPa} / \mathrm{L} / \mathrm{s}$ to be $(-0.16 \pm 0.16,-0.06 \pm 0.11,-0.06$ \pm 0.08 ) in resistance at $5 \mathrm{~Hz}(\mathrm{R} 5), \mathrm{R} 5-20$ (the difference between R5 and R20) and resistance at 20Hz (R20), respectively. Statistical analysis was not performed to assess the relevance of the changes. Changes in other common oscillometry parameters such as reactance at $5 \mathrm{~Hz}(\mathrm{X} 5)$ were not reported. The mean change in $\mathrm{FEV}_{1}$ 


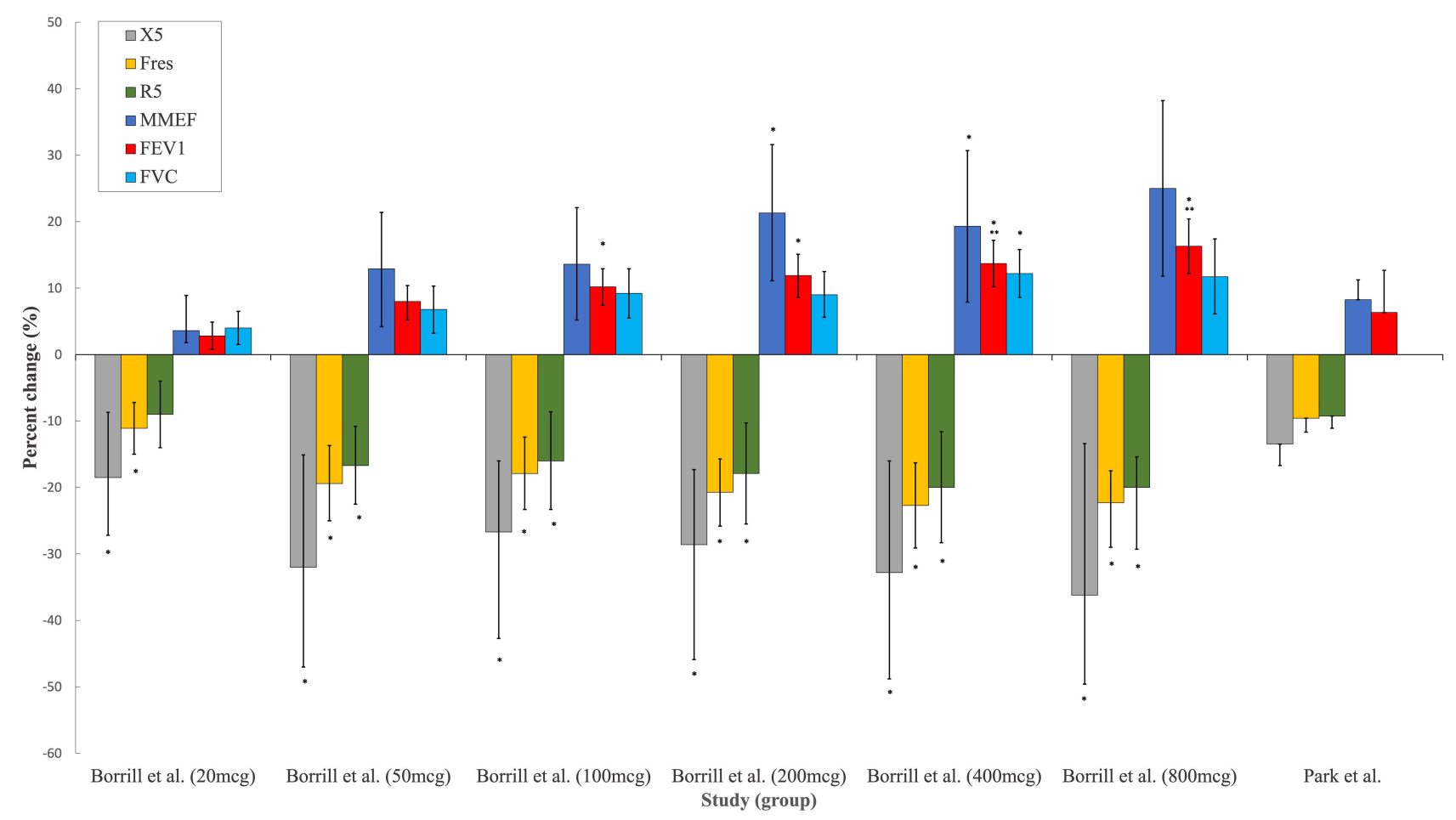

Figure 3 The \% of change in spirometry indices (MMEF, FEV , and FVC) and in oscillometry indices (X5, Fres, and R5) in COPD patients. Notes: Vertical axis is \% of change in spirometry indices and oscillometry indices across different doses of salbutamol Borrill et al. ${ }^{26}$ Data presented in the figure are mean $(95 \% \mathrm{Cl})$ for Borrill et $\mathrm{al}^{26}$ and mean and standard error for Park et al ${ }^{45}$ *BDR is statistically significant. **BDR is clinically significant according to ATS/ERS criteria. Abbreviations: MMEF, mean mid-maximal expiratory flow; $\mathrm{FEV}_{1}$, forced expiratory volume in I second; FVC, forced vital capacity; mcg, microgram. X5, reactance at 5 hertz; Fres, resonant frequency; R5, resistance at 5 hertz; FEV , forced expiratory volume in I second.

was $0.20 \pm 0.25 \mathrm{~L}$, meeting average ATS/ERS criteria for significant BDR.

Nair et $\mathrm{al}^{39}$ conducted a study to compare the BDR in asthmatic and healthy controls using spirometry and oscillometry before and 15 minutes after using Salbutamol 400 mcg delivered via an Accuhaler (DPI). In the asthma group, the mean \% change $(95 \% \mathrm{CI})$ after administering salbutamol was $-33.8(-25.0$ to -42.6$),-20.1(-12.4$ to $-27.8)$ and -73.0 ( -103.8 to -249.7$)$ in R5, R20 and X5, respectively. In the control group, the mean \% change (95\% CI) was $-14.9(-10.0$ to -19.9$),-15.7(-10.4$ to $-21.0)$, and 40.09 (171.7 to -91.4$)$ in R5, R20 and X5, respectively. A mean \% change $(95 \% \mathrm{CI})$ of $6.34 \%$ (7.6 to 5.0) in $\mathrm{FEV}_{1}$ in the asthma group and $2.3 \%$ (3.0 to 1.6) in the healthy controls were found, thus not meeting ATS/ ERS criteria for significant BDR. Baseline values and post-bronchodilator values were reported as \% predicted. The change was reported as the $\%$ of change of from baseline in both oscillometry and spirometry.

In Park et al, ${ }^{45}$ the authors also recruited 30 elderly patients with asthma. BDR was reported as the mean $( \pm$ SEM) percentage change in the absolute values for the following IOS parameters; resonant frequency (Fres), R5,
R20, R5-20, X5 and area of reactance (AX). Results were as follows: $-15.3 \% \pm 2.6$ in Fres, $-12.7 \% \pm 2.7$ in $\mathrm{R} 5$, $-6.4 \% \pm 2.6$ in $\mathrm{R} 20,-10.3 \% \pm 2.6$ in $\mathrm{R} 5-\mathrm{R} 20,-5.9 \% \pm$ 7.3 in $\mathrm{X} 5$, and $-22.9 \% \pm 7.3$ in AX. In comparison, the $\%$ change in $\mathrm{FEV}_{1}$ was reported as $9.2 \% \pm 1.9$. In Figure 4, a bar chart of the percentage of change is provided.

\section{COPD}

Two studies reported BDR using oscillometry in COPD patients. $^{26,45}$ Borrill et $\mathrm{al}^{26}$ compared different lung function tests to determine the most reliable method for identifying BDR in COPD. In this study, IOS parameters R5, R20, X5 and Fres (abbreviated in the study to RF) were evaluated following the administration of ascending doses of salbutamol. X5 and Fres showed statistically significant improvements after $20 \mathrm{mcg}$, but only after $50 \mathrm{mcg}$ in R5. Although R20 showed changes at all doses, they were not statistically significant (see Table 2). The changes of IOS parameters showed significant improvements across several doses, as shown in Figure 3. As described previously, $\mathrm{FEV}_{1}$ also showed statistically significant changes after $100 \mathrm{mcg}$ but only met the ATS/ERS criteria for significant of BDR after $400 \mathrm{mcg}$ and $800 \mathrm{mcg}$. In this study, all IOS 


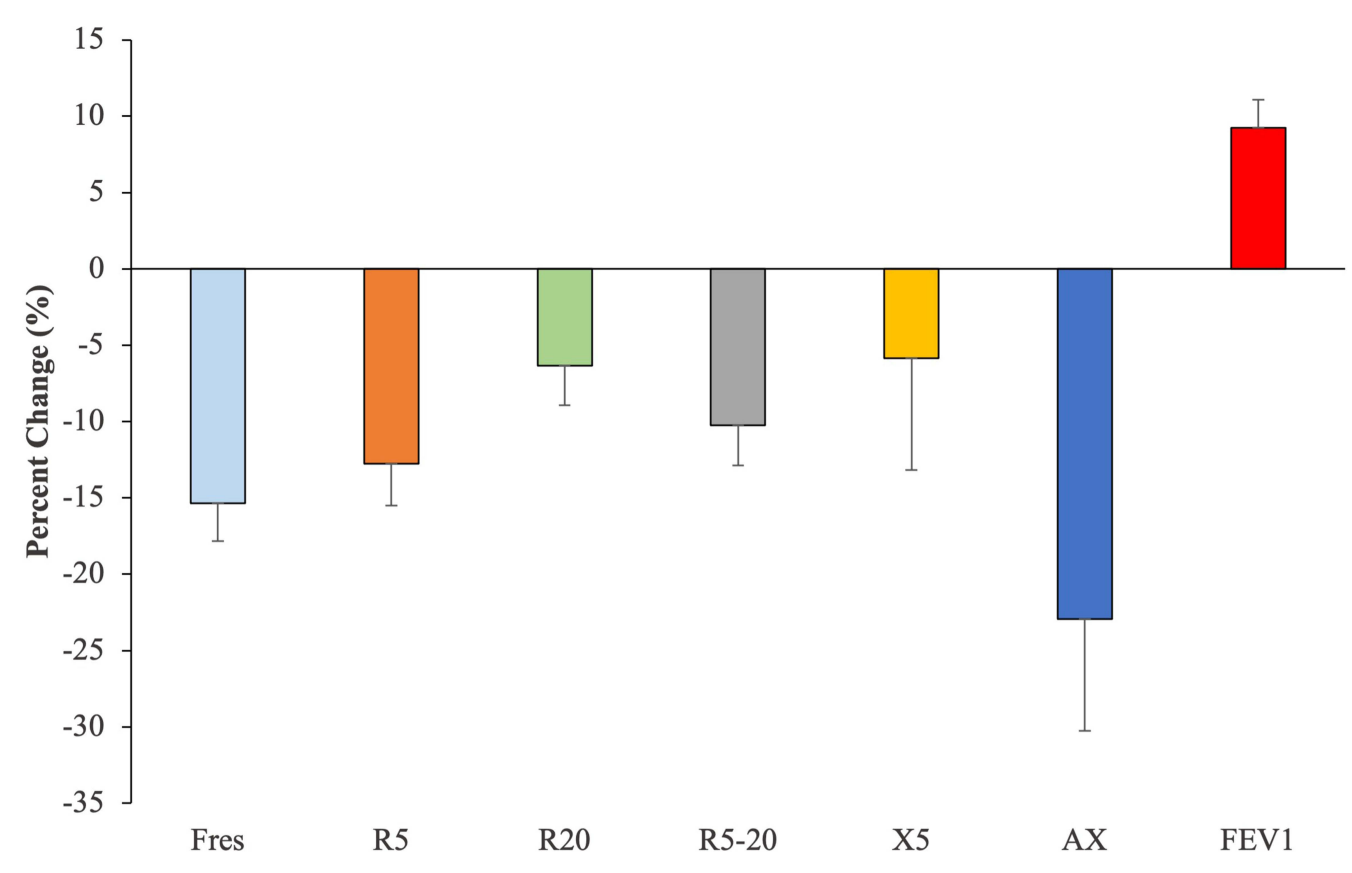

\section{Lung function measures}

Figure 4 The percentage change of IOS parameters and FEV, in Asthmatic patients following BDR.

Notes: Vertical axis is \% of change in oscillometry parameters in comparison to FEV in asthmatic patients. Data is adapted from Park et al. ${ }^{45}$ Data presented in the figure are the mean \% change ( \pm standard error of mean (SEM)).

Abbreviations: X5, reactance at 5 hertz; Fres, resonant frequency; R5, resistance at 5 hertz; R20, resistance at 20Hertz; R5-20, the difference between R5 and R20; AX, area of reactance; $F E V_{1}$, forced expiratory volume in I second.

parameters showed higher variability compared to $\mathrm{FEV}_{1}$, with Fres being the least variable.

As previously described, Park et $\mathrm{al}^{45}$ conducted a prospective study to assess the use of IOS in demonstrating BDR and its role as an alternative to spirometry in 40 patients with COPD. The authors reported Fres, R5, R20, R5-20, X5 and AX. In this study, although statistical significance for the changes was not reported, IOS parameters showed notable mean $\%$ change. The mean \% change (SEM) for X5, AX and Fres was -13.5 (3.2), -22.7 (4.5) and -9.6 (2.1), respectively. The mean \% change (SEM) for R5, R20 and R5-20 was -9.3 (1.8), -6.8 (1.6) and -8.5 (1.6), respectively. In contrast, $\mathrm{FEV}_{1}$ had a mean \% change of 6.3 (1.0), although the ATS/ERS BDR significance level was not met (see Figure 3).

\section{Discussion}

To the best of our knowledge, this the first systematic review to consider evidence for tests of SAF to assess BDR in asthmatic and COPD patients. The studies included varied in design and patient demographics. In most of the studies, the diagnoses of asthma and COPD followed GINA and GOLD criteria, although the diagnostic criteria were not formally reported in other studies. There was heterogeneity of the small airways tests used, the devices, and the reported outcomes. Furthermore, in most of the studies, different bronchodilators, delivery systems, doses, interval times and measurements were used. Hence, it is challenging to draw any conclusion to address whether tests of small airways could be used in the assessment of BDR. Moreover, the high study heterogeneity prohibited a meta-analysis.

In general, there is no clear consensus on how BDR tests should be conducted despite a number of published guidelines. Indeed, most of the studies included in this review had different methodologies for assessing BDR, which limits the certainty of evidence. As there are specific cut-off values for BDR significance, there should be a clear test procedure including aerosol device, time between tests, medication, and dosage. Moreover, the criteria of reporting the change are not clear. The ATS guidelines suggest reporting the absolute change and percentage of change but did not indicate where the percentage is derived, ie, $\%$ predicted or absolute values. ${ }^{2}$ In the latest Association for Respiratory Technology \& Physiology (ARTP), UK statement on pulmonary function testing, it 
was highlighted that there are six different methods for calculating the BDR change. ${ }^{46}$ Nevertheless, it was proposed that the use of z-score or change of \% predicted should be used as it may avoid age, height, and sex bias of the results. ${ }^{46}$

In six of the studies, ${ }^{35,36,38,40,43,44}$ means were reported despite the data being clearly skewed, weakening the evidence presented in this review. This variance is due to the inherent variability of SAF tests and to the effortdependence in spirometry. In such cases, median and interquartile range should have been used.

Current asthma guidelines, such as the BTS and GINA include BDR of $\mathrm{FEV}_{1}$ to diagnose asthma and differentiate it from other respiratory diseases such as COPD. However, the criteria to identify BDR $(>12 \%$ and $>200 \mathrm{~mL})$ in $\mathrm{FEV}_{1}$ is not always observed in asthmatic patients. ${ }^{17}$ In addition, this level of BDR has also been reported in patient with COPD. ${ }^{17}$ Furthermore, the assessment of BDR using FEV 1 demonstrates high inter-patient and intra-patient variability in asthmatic and COPD patients, limiting its specificity or sensitivity in discriminating COPD from asthma. ${ }^{47,48}$ It has been proposed that the use of grading in assessing the BDR is more valuable than using a simple cutoff value as evidence shows that BDR relates to clinical outcomes such as exacerbation rates or quality of life. ${ }^{49,50}$ $\mathrm{FEV}_{1}$ is considered an assessment of larger airways function, although it can reflect major small airway dysfunction/loss. Evidence shows that small airways are affected in asthma ${ }^{51}$ and dysfunction at this site increases with GINA-based severity. ${ }^{52}$

The reported studies suggested differences in BDR between larger and small airways, depending on disease severity. In general, in mild to moderate disease, small airways showed greater BDR expressed as a change in $\mathrm{L} / \mathrm{s}$ than overall airways (assessed by $\mathrm{FEV}_{1}$ in $\mathrm{L}$ ). In severe cases, a different pattern was seen with larger airways reflecting higher BDR, suggesting a fixed obstruction, loss of the small airways or a decrease in aerosol delivery to the small airways due to an increased obstruction in the large airways. These findings also align with the hypothesis that small airways are affected early ${ }^{53}$ in obstructive lung diseases and SAF tests should, therefore, be considered in their assessment.

In the studies of asthmatic patients, higher variance in BDR results were seen most in MMEF and $\mathrm{FEF}_{50}$ compared to $\mathrm{FEV}_{1}$. Using MMEF, the small airways response to bronchodilator showed greater changes than $\mathrm{FEV}_{1}$ in COPD patients and, in one study, it was shown that the changes were greater in higher BD doses. ${ }^{26}$ In one study, however, MMEF changes had higher variability than $\mathrm{FEV}_{1}{ }^{26}$ Therefore, the variability seen in studies using $\mathrm{MMEF}$ and $\mathrm{FEF}_{50}$ may impose a challenge to implement these measures in the assessment of BDR. Moreover, when assessing the BDR in MMEF, current guidelines suggest correction to the FVC (which influences the MMEF), ${ }^{2}$ yet none of the included studies have reported this correction. The need to correct MMEF to FVC makes its use in the BDR assessment challenging.

As for $\mathrm{FEV}_{1}$, obtaining $\mathrm{MMEF}$ and $\mathrm{FEF}_{50}$ requires a maximal inspiration followed by a forced maximal expiration, which is effort-dependent and the maneuver itself can result in changes in airway tone. ${ }^{54,55}$ Oscillometry can overcome this limitation, as this test is effort-independent. In asthmatic patients, oscillometry showed a decrease in all resistance parameters (R5, R20, R5-R20, relating to total, large and small airways resistance, respectively) after the administration of a bronchodilator. The greatest change seen was in the total resistance (R5) in the two studies that reported this technique in asthma, indicating the reversibility nature of the airways in asthmatic patients including the small airways. However, there are inconsistencies in how results are reported. For example, Nair et $\mathrm{al}^{39}$ reported only the $\%$ of predicted values for oscillometry, leading to some values being $>400 \%$ and limiting the ability to compare these results to other published literature which have used different parameters.

In COPD, IOS was used in two studies, demonstrating BDR and improvement in X5, R5, Fres, R5-20 and AX, with $\mathrm{X} 5$ and $\mathrm{AX}$ showing the most pronounced improvements compared to other IOS parameters. In the study by Borrill et $\mathrm{al}^{26}$ the $\%$ change of $\mathrm{R} 5, \mathrm{X} 5$, and Fres was greater than $\mathrm{FEV}_{1}$ across all doses given to patients but there was not data to support the clinical implications of the changes seen. In the study by Park et al, ${ }^{45}$ all IOS parameters (including R5-20) demonstrated greater \% changes compared $\mathrm{FEV}_{1}$, with the greatest seen in $\mathrm{AX}$ and X5. In this study, however, the changes of IOS parameters were lower compared to the findings in Borrill et al, which may be because of differences in aerosol delivery methods (pMDI vs Dosimeter) or differences in patient demography with this study including an older population. In oscillometry, higher oscillation frequencies $(>15 \mathrm{~Hz})$ do not penetrate the small airways, which play a central role in the pathophysiology of COPD. ${ }^{27,28} \mathrm{As}$ resistance at higher frequency relates to the larger airways it was shown to be unrelated to the obstruction in COPD 
and explains why R20 did not show significant changes in these studies. The changes of X5, AX and Fres may be associated with the improvement of small airway patency, resulting in a reduction in hyperinflation and, hence, lung volume, consequently leading to an increase in lung compliance.

In summary, these studies suggest that oscillometry may detect significant BDR that is not detected by changes in $\mathrm{FEV}_{1}$. However, in the study by Borrill et al, ${ }^{26}$ IOS parameters had both a higher within test and within day variability than $\mathrm{FEV}_{1}$ and, therefore, were less reproducible. In this study, only 24 COPD patients were included, and further larger studies are needed to determine the variabilities of these measurements. In general, oscillometry lacks knowledge of sensitivity as well as the reference ranges for multi-ethnic adults. ${ }^{56}$ Moreover, using different devices may affect oscillometry results. ${ }^{51}$ Although new oscillometry devices can separate inspiratory and expiratory parameters (which may provide an evaluation of expiratory flow limitation), oscillometry is relatively expensive compared to spirometry and may require training. Therefore, these limitations may generally hinder the utilization of oscillometry in clinical practice. Although some studies have suggested different BDR threshold for some oscillometry parameters, ${ }^{56-58}$ the evidence of recognized BDR guidelines is still lacking. Thus, oscillometry is less attractive for BDR assessment compared to traditional spirometry measures $\left(\mathrm{FEV}_{1}\right.$ and $\left.\mathrm{FVC}\right)$, which has been solely used and engrained into clinical practice.

Although the systematic protocol did not plan to assess the differences in BDR between asthma and COPD, Park et $\mathrm{al}^{45}$ compared BDR by IOS for COPD and asthmatic patients with no statistical differences found between these groups. However, findings are limited as, firstly, due to the narrow demography of included patients (older than 70 years in both groups), which might impede discrimination between the two diseases. ${ }^{52}$ Secondly, in the post-hoc analysis, they grouped asthma and ACOS together despite the clinical differences between the conditions, ${ }^{59}$ meaning it is not possible to draw conclusions on the comparison of BDR in asthma versus COPD.

\section{Limitations and Implication for Research and Clinical Practice}

This systematic review is limited by the small number of included studies, the differences in studies design, the use of different small airway tests and the different outcomes reported. Other differences also limit the evidence presented in this review, such as the use of different medications, doses, drug delivery devices and time interval to testing. Many factors have been reported that may alter the deposition of aerosolized drugs and there are differences in efficiencies among them. ${ }^{60}$ Time interval between bronchodilator administration and testing has been reported to be an important aspect in assessing the lung function $^{61}$ and yet there is no consistency between the studies reported here. Collectively, these limitations make comparison across the included studies impossible. Studies also did not report the demographics of participants in detail, with most not reporting ethnicity. We found that there is a statistically significant BDR demonstrated for both the small and larger airways in both asthmatic and COPD patients, but the implications are obscure. More research is needed to assess and quantify the response to extra-fine particle bronchodilators that are thought to have a greater role in the peripheral airways. However, there is a real need to define the sensitivity of the tests and, moreover, to understand what is a clinically important change for tests of SAF. This would include further assessment of whether/when agreed BDR in small airways might be important and associated with a demonstrable clinical or research benefit. Furthermore, asthma and COPD are both heterogeneous diseases in terms of pathology, clinical phenotype, and disease progression. Therefore, it is possible that small airway responsiveness in COPD may identify a subgroup of patients, namely those with patent though impaired small airways rather than those who have lost small airways. Such patients could be managed differently as they are likely to have increased therapeutic benefit using bronchodilators.

\section{Conclusion}

In asthma and COPD, there is evidence supporting the potential use of BDR measured using tests of SAF. However, the evidence to date is limited by the lack of consensus as to which bronchodilator should be used, at what dose, by which delivery mode, the time interval between drug administration, how to report BDR test results and the clinical impact of any change (minimal clinically important difference). Oscillometry is effort-independent and, hence, could be a method of choice but it remains limited due to the lack of reference ranges for multi-ethnic adults, variability, and sensitivity to change as well as limited knowledge on the clinical impact with respect to a significant BDR. MMEF is highly variable but has shown some potential, especially in mild 
asthma but is unlikely to be clinically useful in assessing BDR without the recommended isovolumetric correction, which is a far more specialized technique. Oscillometry may also be useful, particularly for patients who are unable to perform spirometry, but the difference in hardware, the use of different frequencies (in the higher range) and the different units in which the parameters are reported are all major challenges in the development of standardized guidelines for assessing BDR. Moreover, SAF techniques that are not integral to basic spirometry require additional costs that are usually much higher than the cost of a spirometer. For these reasons, tests of SAF are currently less attractive for the assessment of BDR than the traditional spirometry parameters $\mathrm{FEV}_{1}$ and $\mathrm{FVC}$, which are deeply ingrained in general clinical practice. There is a need for robust evidence of a clear benefit to using SAF tests instead of or as an adjunct to the $\mathrm{FEV}_{1}$ along with published guidelines that define a significant BDR before there is any chance of their adoption into routine practice.

\section{Abbreviations}

COPD, chronic obstructive pulmonary disease; ATS, American Thoracic Society; ERS, European Thoracic Society; FVC, forced vital capacity; $\mathrm{FEV}_{1}$, forced expiratory volume in the first second; MMEF, maximal midexpiratory flow; SABA, short-acting beta2 agonists; BDR, bronchodilator response; pMDI, pressurized metered dose inhalers; SAMA, short-acting muscarinic antagonists; SAF, small airways function; PRISMA, Preferred Reporting Items for Systematic Reviews and Meta-Analyses; FOT, forced oscillometry; IOS, impulse oscillometry; $\mathrm{FEF}_{25-75}$, forced expiratory flow between $25 \%$ and $75 \%$ of $\mathrm{FVC} ; \mathrm{FEF}_{50}$, forced expiratory flow at $50 \%$ of FVC; SBW, single breath washout; RCT, randomized controlled trials; GINA, Global Initiative of Asthma; GOLD, Global Initiative for Chronic Obstructive Lung Disease; SVN, small volume jet nebulizers; DPI, dry powder inhalers; SD, standard deviation; $\mathrm{R} 5$, resistance at 5Hz; R5-R20, the difference between R5 and R20; R20, resistance at $20 \mathrm{~Hz} ; \mathrm{X} 5$, reactance at $5 \mathrm{~Hz}$; Fres, resonant frequency; AX, area of reactance; ARTP, Association for Respiratory Technology \& Physiology.

\section{Disclosure}

Prof. Dr. Elizabeth Sapey reports grants from MRC, Wellcome Trust, HDRUK, British Lung Foundation, Alpha 1 Foundation, and NIHR, outside the submitted work. The authors report no other conflicts of interest in this work.

\section{References}

1. Chhabra SK. Test of reversibility of airway obstruction: time for a review? Editorial. Lung India. 2013;30(1):3-4. doi:10.4103/09702113.106118

2. Graham BL, Steenbruggen I, Miller MR, et al. Standardization of spirometry 2019 update. An Official American Thoracic Society and European Respiratory Society technical statement. Am J Respir Crit Care Med. 2019;200(8):e70-e88. doi:10.1164/rccm.201908-1590ST

3. Higham A, Quinn AM, Cancado JED, Singh D. The pathology of small airways disease in COPD: historical aspects and future directions. Respir Res. 2019;20(1):49. doi:10.1186/s12931-019-1017-y

4. Usmani OS, Singh D, Spinola M, Bizzi A, Barnes PJ. The prevalence of small airways disease in adult asthma: a systematic literature review. Respir Med. 2016;116:19-27. doi:10.1016/j.rmed.2016.05.006

5. BTS/SIGN. British guideline on the management of asthma. Available from: https://www.brit-thoracic.org.uk/quality-improve ment/guidelines/asthma/. Accessed October 30, 2020.

6. Quanjer PH, Weiner DJ, Pretto JJ, Brazzale DJ, Boros PW. Measurement of FEF25-75\% and FEF75\% does not contribute to clinical decision making. Eur Respir J. 2014;43(4):1051-1058. doi:10.1183/09031936.00128113

7. Miller MR, Hankinson J, Brusasco V, et al. Standardisation of spirometry. Eur Respir J. 2005;26(2):319. doi:10.1183/09031936.05.00034805

8. Coates AL, Allen PD, MacNeish CF, Ho SL, Lands LC. Effect of size and disease on estimated deposition of drugs administered using jet nebulization in children with cystic fibrosis. Chest. 2001;119 (4):1123-1130. doi:10.1378/chest.119.4.1123

9. Newhouse MT. Asthma therapy with aerosols: are nebulizers obsolete? A continuing controversy. $J$ Pediatr. 1999;135(1):5-8. doi:10.1016/s0022-3476(99)70317-3

10. Molimard M, Bourcereau J, Le Gros V, Bourdeix I. Total reversibility testing as indicator of the clinical efficacy of formoterol in COPD. Respir Med. 2005;99(6):695-702. doi:10.1016/j.rmed.2004.11.009

11. Calverley PMA, Burge PS, Spencer S, Anderson JA, Jones PW. Bronchodilator reversibility testing in chronic obstructive pulmonary disease. Thorax. 2003;58(8):659. doi:10.1136/thorax.58.8.659

12. National Institute for Health Care Excellence (NICE). Diagnosis: Bronchodilator Reversibility. National Institute for Health and Care Excellence (UK); 2017.

13. Tweeddale PM, Alexander F, McHardy GJ. Short term variability in FEV1 and bronchodilator responsiveness in patients with obstructive ventilatory defects. Thorax. 1987;42(7):487-490. doi:10.1136/ thx.42.7.487

14. Pellegrino R, Viegi G, Brusasco V, et al. Interpretative strategies for lung function tests. Eur Respir J. 2005;26(5):948-968. doi:10.1183/ 09031936.05.00035205

15. British Thoracic Society. BTS guidelines for the management of chronic obstructive pulmonary disease. The COPD Guidelines Group of the Standards of Care Committee of the BTS. Thorax. 1997;52(Suppl 5):S1-S28. doi:10.1136/thx.52.2008.S1.5

16. Chhabra SK. Acute bronchodilator response has limited value in differentiating bronchial asthma from COPD. J Asthma. 2005;42 (5):367-372. doi:10.1081/JAS-62992

17. Janson C, Malinovschi A, Amaral AFS, et al. Bronchodilator reversibility in asthma and COPD: findings from three large population studies. Eur Respir J. 2019;54:1900561. doi:10.1183/139930 03.00561-2019

18. Albert P, Agusti A, Edwards L, et al. Bronchodilator responsiveness as a phenotypic characteristic of established chronic obstructive pulmonary disease. Thorax. 2012;67(8):701. doi:10.1136/thoraxjnl2011-201458 
19. Tan WC, Vollmer WM, Lamprecht B, et al. Worldwide patterns of bronchodilator responsiveness: results from the Burden of Obstructive Lung Disease study. Thorax. 2012;67(8):718-726. doi:10.1136/thoraxjnl-2011-201445

20. Denlinger LC, Phillips BR, Ramratnam S, et al. Inflammatory and comorbid features of patients with severe asthma and frequent exacerbations. Am J Respir Crit Care Med. 2017;195(3):302-313. doi:10.1164/rccm.201602-0419OC

21. Galant SP, Morphew T, Newcomb RL, Hioe K, Guijon O, Liao O. The relationship of the bronchodilator response phenotype to poor asthma control in children with normal spirometry. $J$ Pediatr. 2011;158(6):953-959 e1. doi:10.1016/j.jpeds.2010.11.029

22. Almeshari MA, Alobaidi NY, Edgar RG, Stockley J, Sapey E. Physiological tests of small airways function in diagnosing asthma: a systematic review. BMJ Open Respir Res. 2020;7(1):e000770. doi:10.1136/bmjresp-2020-000770

23. O'Donnell DE, Revill SM, Webb KA. Dynamic hyperinflation and exercise intolerance in chronic obstructive pulmonary disease. $A m J$ Respir Crit Care Med. 2001;164(5):770-777. doi:10.1164/ajrccm.1 64.5.2012122

24. Schermer T, Heijdra Y, Zadel S, et al. Flow and volume responses after routine salbutamol reversibility testing in mild to very severe COPD. Respir Med. 2007;101(6):1355-1362. doi:10.1016/j. rmed.2006.09.024

25. Wouters EFM, Verschoof AC, Polko AH, Visser BF. Impedance measurements of the respiratory system before and after salbutamol in COPD patients. Respir Med. 1989;83(4):309-313. doi:10.1016/ S0954-6111(89)80202-1

26. Borrill ZL, Houghton CM, Woodcock AA, Vestbo J, Singh D. Measuring bronchodilation in COPD clinical trials. Br J Clin Pharmacol. 2005;59 (4):379-384. doi:10.1111/j.1365-2125.2004.02261.x

27. Bosken CH, Wiggs BR, Paré PD, Hogg JC. Small airway dimensions in smokers with obstruction to airflow. Am Rev Respir Dis. 1990;142 (3):563-570. doi:10.1164/ajrccm/142.3.563

28. Hogg JC, Macklem PT, Thurlbeck WM. Site and nature of airway obstruction in chronic obstructive lung disease. $N$ Engl J Med. 1968;278(25):1355-1360. doi:10.1056/nejm196806202782501

29. Stockley JA, Ismail AM, Hughes SM, Edgar R, Stockley RA, Sapey E. Maximal mid-expiratory flow detects early lung disease in alpha1antitrypsin deficiency. Eur Respir J. 2017;49(3):1602055. doi:10.1183/13993003.02055-2016

30. Papi A, Vestbo J, Fabbri L, et al. Extrafine inhaled triple therapy versus dual bronchodilator therapy in chronic obstructive pulmonary disease (TRIBUTE): a double-blind, parallel group, randomised controlled trial. Lancet. 2018;391(10125):1076-1084. doi:10.1016/ S0140-6736(18)30206-X

31. Liberati A, Altman DG, Tetzlaff J, et al. The PRISMA statement for reporting systematic reviews and meta-analyses of studies that evaluate healthcare interventions: explanation and elaboration. $B M J$ 2009;339:b2700. doi:10.1136/bmj.b2700

32. Ouzzani M, Hammady H, Fedorowicz Z, Elmagarmid A. Rayyan-a web and mobile app for systematic reviews. Syst Rev. 2016;5(1):210. doi:10.1186/s13643-016-0384-4

33. Sterne JAC, Savović J, Page MJ, et al. RoB 2: a revised tool for assessing risk of bias in randomised trials. BMJ. 2019;366:14898. doi: $10.1136 / \mathrm{bmj} .14898$

34. National Heart, Lung, and Blood institute. Study quality assessment tools. Available from: https://www.nhlbi.nih.gov/health-topics/studyquality-assessment-tools. Accessed October 19, 2021.

35. El-Khatib MF, Jamaleddine G, Kanj N, et al. Effect of heliox- and air-driven nebulized bronchodilator therapy on lung function in patients with asthma. Lung. 2014;192(3):377-383. doi:10.1007/ s00408-014-9570-0

36. Fakharian A, Fahimi F, Salamzadeh J, Mohammadi M, Masjedi MR. Spirometric improvements with two commonly used spacers in asthmatic patients. Tanaffos. 2008;7(3):37-40.
37. Lipworth BJ, Clark DJ. Effects of airway calibre on lung delivery of nebulised salbutamol. Thorax. 1997;52(12):1036-1039. doi:10.1136/ thx.52.12.1036

38. Mariotta S, Sposato B, Ricci A, Bruno P, Aquilini M, Mannino F. Reversibility test in the early stages of bronchial asthma. $J$ Asthma. 2005;42(6):487-491. doi:10.1081/JAS-67536

39. Nair A, Ward J, Lipworth BJ. Comparison of bronchodilator response in patients with asthma and healthy subjects using spirometry and oscillometry. Ann Allerg Asthma Immunol. 2011;107(4):317-322. doi:10.1016/j.anai.2011.07.011

40. Ohwada A, Inami K, Onuma E, Matsumoto-Yamazaki M, Atsuta R, Takahashi K. Bronchial reversibility with a short-acting beta2-agonist predicts the FEV1 response to administration of a long-acting beta2agonist with inhaled corticosteroids in patients with bronchial asthma. Exp Ther Med. 2011;2(4):619-623. doi:10.3892/etm.2011.268

41. Rajkumar VHK, Gaur SN. Comparative evaluation of market spacer and home made spacer in the management of bronchial asthma. $J$ Assoc Phys India. 2002;50:397-399.

42. Schecker MH, Wilson AF, Mukai DS, Hahn M, Crook D, Novey HS. A device for overcoming discoordination with metered-dose inhalers. J Allerg Clin Immunol. 1993;92(6):783-789. doi:10.1016/0091-6749 (93) $90054-\mathrm{j}$

43. Tavares e Castro A, Matos P, Tavares B, Matos MJ, Segorbe-Luis A. Alternative functional criteria to assess airflow-limitation reversibility in asthma. Rev Port Pneumol. 2015;21(2):69-75. doi:10.1016/j. rppnen.2014.08.002

44. Yaegashi M, Yalamanchili VA, Kaza V, Weedon J, Heurich AE, Akerman MJ. The utility of the forced oscillation technique in assessing bronchodilator responsiveness in patients with asthma. Respir Med. 2007;101(5):995-1000. doi:10.1016/j.rmed.2006.09.001

45. Park JH, Lee JH, Kim HJ, et al. Usefulness of impulse oscillometry for the assessment of bronchodilator response in elderly patients with chronic obstructive airway disease. J Thorac Dis. 2019;11(4):14851494. doi: $10.21037 /$ jtd.2019.03.34

46. Sylvester KP, Clayton N, Cliff I, et al. ARTP statement on pulmonary function testing 2020. BMJ Open Respir Res. 2020;7(1):e000575. doi:10.1136/bmjresp-2020-000575

47. Kesten S, Rebuck AS. Is the short-term response to inhaled betaadrenergic agonist sensitive or specific for distinguishing between asthma and COPD? Chest. 1994;105(4):1042-1045. doi:10.1378/ chest.105.4.1042

48. Han MK, Wise R, Mumford J, et al. Prevalence and clinical correlates of bronchoreversibility in severe emphysema. Eur Respir J. 2010;35(5):1048. doi:10.1183/09031936.00052509

49. Ioachimescu OC, Ramos JA, Hoffman M, McCarthy K, Stoller JK. Assessing bronchodilator response by changes in per cent predicted forced expiratory volume in one second. J Investig Med. 2021;69 (5):1027-1034. doi:10.1136/jim-2020-001663

50. Hansen JE, Dilektasli AG, Porszasz J, et al. A new bronchodilator response grading strategy identifies distinct patient populations. Ann Am Thorac Soc. 2019;16(12):1504-1517. doi:10.1513/AnnalsATS.201901$030 \mathrm{OC}$

51. Dandurand RJ, Lavoie J-P, Lands LC, Hantos Z. Comparison of oscillometry devices using active mechanical test loads. ERJ Open Res. 2019;5(4):00160-2019. doi:10.1183/23120541.00160-2019

52. Fabbri LM, Romagnoli M, Corbetta L, et al. Differences in airway inflammation in patients with fixed airflow obstruction due to asthma or chronic obstructive pulmonary disease. Am J Respir Crit Care Med. 2003;167(3):418-424. doi:10.1164/rccm.200203-183OC

53. Jiang D, Wang Z, Shen C, et al. Small airway dysfunction may be an indicator of early asthma: findings from high-resolution CT. Ann Allerg Asthma Immunol. 2019;122(5):498-501. doi:10.1016/j. anai.2019.02.024

54. Suzuki S, Miyashita A, Matsumoto Y, Okubo T. Bronchoconstriction induced by spirometric maneuvers in patients with bronchial asthma. Ann Allergy. 1990;65(4):315-320. 
55. Froeb HF, Mead J. Relative hysteresis of the dead space and lung in vivo. $J$ Appl Physiol. 1968;25(3):244-248. doi:10.1152/jappl.1968.25.3.244

56. Oostveen E, Boda K, van der Grinten CP, et al. Respiratory impedance in healthy subjects: baseline values and bronchodilator response. Multicenter study. Eur Respir J. 2013;42(6):1513-1523. doi:10.1183/09031936.00126212

57. Houghton CM, Woodcock AA, Singh D. A comparison of lung function methods for assessing dose-response effects of salbutamol. Br J Clin Pharmacol. 2004;58(2):134-141. doi:10.1111/j.13652125.2004.02105.x

58. Houghton CM, Woodcock AA, Singh D. A comparison of plethysmography, spirometry and oscillometry for assessing the pulmonary effects of inhaled ipratropium bromide in healthy subjects and patients with asthma. Br J Clin Pharmacol. 2005;59(2):152-159. doi:10.1111/j.1365-2125.2004.2262.x
59. Tommola M, Ilmarinen P, Tuomisto LE, et al. Differences between asthma-COPD overlap syndrome and adult-onset asthma. Eur Respir $J$. 2017;49(5):1602383. doi:10.1183/13993003.02383-2016

60. Ari A. Jet, ultrasonic, and mesh nebulizers: an evaluation of nebulizers for better clinical outcomes. Eur J Pulmonol. 2014;16:1-7. doi:10.5152/ejp.2014.00087

61. Cavallazzi RS, Polivka BJ, Beatty BL, et al. Current bronchodilator responsiveness criteria underestimate asthma in older adults. Respir Care. 2020;65:1104-1111. doi:10.4187/respcare.07132

62. Moher D, Liberati A, Tetzlaff J, Altman DG. Preferred reporting items for systematic reviews and meta-analyses: the PRISMA statement. PLoS Med. 2009;6(7):e1000097. doi:10.1371/journal.pmed.1000097

\section{Publish your work in this journal}

The International Journal of COPD is an international, peer-reviewed journal of therapeutics and pharmacology focusing on concise rapid reporting of clinical studies and reviews in COPD. Special focus is given to the pathophysiological processes underlying the disease, intervention programs, patient focused education, and self management protocols. This journal is indexed on PubMed Central, MedLine and CAS. The manuscript management system is completely online and includes a very quick and fair peer-review system, which is all easy to use. Visit http://www.dovepress.com/testimonials.php to read real quotes from published authors. 